\title{
CONSCIENTIOUSNESS DAN AGREEABLENESS SEBAGAI PEMODERASI PENGARUH LOVE OF MONEY PADA TAX EVASION TENDENCY MAHASISWA MAGISTER AKUNTANSI
}

\author{
Marce Sherly Kase ${ }^{1}$ \\ Herkulanus Bambang Suprasto ${ }^{2}$ \\ Maria M. Ratna Sari ${ }^{3}$ \\ 1,2,3 Fakultas Ekonomi dan Bisnis Universitas Udayana (Unud), Bali, Indonesia \\ Email: kase.sherly@gmail.com.
}

\begin{abstract}
ABSTRAK
Tujuan penelitian ini untuk menguji pengaruh love of money pada tax evasion tendency dengan conscientiousness dan agreeableness sebagai pemoderasi. Populasi dalam penelitian ini adalah Mahasiswa Magister Akuntansi Universitas Udayana. Pemilihan sampel dengan metode nonprobability sampling dengan teknik purposive sampling diperoleh 85 orang. Data dianalisis menggunakan Moderated Regression Analysis (MRA). Hasil penelitian menunjukkan bahwa love of money berpengaruh positif pada tax evasion tendency. Hasil analisis regresi moderasi menunjukkan bahwa conscientiousness tidak memoderasi pengaruh love of money pada tax evasion tendency dan agreeableness memoderasi pengaruh love of money pada tax evasion tendency.
\end{abstract}

Kata kunci: Love of Money, Tax Evasion Tendency, Conscientiousness, Agreeableness

\begin{abstract}
This study aims to test the moderating effect of conscientiousness and agreeableness in the relationship between love of money and tax evasion tendency. The population in this study is graduate student of accounting of Udayana University. The sample selection method is nonprobability sampling with purposive sampling technique in order to obtain 85 people. Data were analyzed using Moderated Regression Analysis (MRA). The result of regression analyses show that love of money is positively related to tax evasion tendency. Agreeableness is also found to moderate the relationship between love of money and tax evasion tendency but conscientiousness is not a moderator in this relationship.
\end{abstract}

Keywords: Love of Money, Tax Evasion Tendency, Conscientiousness, Agreeableness 


\section{PENDAHULUAN}

Perguruan tinggi yang merupakan penghasil sumber daya manusia yang profesional, diharapkan dapat memenuhi kebutuhan pasar yang ada, oleh karena itu dituntut untuk menghasilkan tenaga profesional yang memiliki kualifikasi keahlian sesuai dengan bidang ilmunya dan memiliki perilaku etis yang tinggi. (Hastuti, 2007). Seorang sarjana akuntansi yang menekuni profesi akuntan baik sebagai akuntan manajemen, akuntan publik, akuntan sektor publik, akuntan pendidik, dan akuntan freelance (Widarno, 2007) dituntut untuk memiliki kewajiban dalam mempertahankan kode etik akuntan (Nugrahaningsih, 2005).

Profesi akuntan sangat rentan terhadap pelanggaran etika (Kamayanti \& Widyaningrum, 2013), terjadinya pelanggaran etika disebabkan karena kurangnya pengetahuan, pemahaman, dan kemauan dalam menerapkan nilai-nilai moral dan etika (Novius, 2008) karena itu pengembangan dan kesadaran etik/moral memainkan peran kunci dalam semua area profesi akuntansi (Muawanah dan Indriantoro, 2001).

Kepercayaan dari masyarakat merupakan dasar bagi akuntan dalam melaksanakan tanggungjawab profesinya. Purnamasari (2006) menyatakan bahwa profesionalisme mensyaratkan tiga hal utama yang harus dimiliki oleh setiap anggota profesi yaitu: keahlian, pengetahuan, dan karakter. Karakter menunjukkan personality (kepribadian) seorang profesional yang diwujudkan dalam sikap dan tindakan etis (Chrismastuti dan Purnamasari, 2004). Tindakan etis akuntan sangat menentukan posisinya di masyarakat sebagai pemakai jasa profesi akuntan (Lucyanda, 2012). Secara profesional dalam menjalankan 
pekerjaannya akuntan harus konsisten menjaga reputasi profesi dan menghindari tindakan yang merendahkan martabat profesinya (Widyasmono, 2012), termasuk menjaga etika dan sikap dari akuntan itu sendiri (Anwar \& Amarullah, 2006).

Tujuan dari pendidikan akuntansi adalah untuk mengenalkan mahasiswa kepada nilai-nilai dan standar-standar etik dalam profesi akuntan (Clikemen \& Henning, 2000). Mastracchio (2005) menyatakan bahwa kepedulian terhadap etika harus diawali dari kurikulum akuntansi, jauh sebelum mahasiswa akuntansi masuk dalam ke dunia profesi akuntansi. Elias (2010) berpendapat bahwa mahasiswa akuntansi sekarang adalah para profesional di masa depan dan dengan pendidikan etika yang baik diharapkan dapat menguntungkan profesinya dalam jangka pajang. Profesi akuntansi memfokuskan perhatiannya pada persepsi etis para mahasiswa akuntansi sebagai titik awal dalam meningkatkan persepsi terhadap profesi akuntansi (Normadewi, 2012).

Analisis terhadap sikap etis dalam profesi akuntansi menunjukkan bahwa akuntan mempunyai kesempatan untuk melakukan tindakan tidak etis dalam profesi mereka (Husein, 2004). Di Indonesia salah satu contoh kasus fenomenal tindakan kecurangan pajak yang dilakukan oleh kasus Gayus Tambunan seorang yang berprofesi akuntansi. Selain itu praktek penggelapan pajak juga semakin meningkat dari tahun ke tahun. Berdasarkan data Dirjen Pajak pada periode 2008-2013 terdapat 100 kasus faktur pajak fiktif dengan potensi kerugian negara Rp 1,5 triliun yaitu tahun 2008 ditemukan tiga kasus dengan kerugian $\mathrm{Rp} 35$ miliar, tahun 2009 terdapat 21 kasus dengan kerugian Rp 257 miliar, tahun 2010 terdapat 21 kasus dengan kerugian 497 miliar, tahun 2011 terdapat 23 kasus 
dengan kerugian 194 miliar, tahun 2012 terdapat 12 kasus dengan kerugian 326 miliar serta tahun 2013 ditemukan 20 kasus dengan kerugian Rp 239 miliar (www.beritasatu.com). Kasus-kasus penyimpangan ini berimplikasi pada menurunnya kepercayaan masyarakat terhadap profesi akuntan (Aziz \& Taman, 2015).

Dampak menurunnya kepercayaan pada profesi akuntansi, mengharuskan pendidikan etika harus diberikan secara mendalam kepada mahasiswa sebelum mereka masuk dalam dunia kerja, sehingga akan memberikan nilai positif pada saat mahasiswa dihadapkan pada dilema etis sebagai seorang profesional pada bidang akuntan. Persepsi sangat dipengaruhi oleh pengetahuan sistem nilai yang dimiliki oleh seseorang (Stead, et al, 1990). Khomsiyah dan Indriantoro (1998) menyatakan bahwa setiap individu memiliki personal ethical philosophy yang akan menentukan persepsi etisnya sesuai dengan peran yang disandangkannya. Etika profesi akuntan di Indonesia diatur dalam kode etik akuntan. Kode etik ini menjadi panduan baik untuk akuntan publik, akuntan pemerintah, akuntan manajemen maupun akuntan pendidik dalam melaksanakan tanggungjawab profesinya (Suliani, 2010).

Salah satu faktor yang dapat mempengaruhi sikap etis seseorang terhadap suatu tindakan pelanggaran adalah uang. Tax evasion tendency yang dilakukan tersebut dapat dipengaruhi oleh kecintaan terhadap uang yang tinggi karena menurut Sloan (2002) dalam Rosianti,dkk (2014) kecintaan terhadap uang merupakan keinginan manusia terhadap uang atau keserakahan, selanjutnya ketika uang ditempatkan sebagai prioritas utama dalam kehidupan sehari-hari maka tax 
evasion adalah tindakan yang dapat diterima (Lau, Choe, dan Tan 2013). Karena pentingnya uang dan interpretasi setiap individu yang berbeda-beda maka Tang (1992) memperkenalkan konsep "love of money" dalam literatur psikologis yang merupakan ukuran perasaan subjektif seseorang tentang uang. Tang dan Chiu (2003) mengemukakan love of money sangat terkait dengan konsep ketamakan, konsep love of money merupakan karakter seseorang yang memuja atau mendewakan uang/materi lebih dari apapun tentu bagi seseorang yang memuja uang/materi dia akan melakukan berbagai cara untuk mendapatkan uang/materi. Tang dan Luna-Arocas (2005) menemukan bahwa love of money dapat membantu memprediksi dan mengendalikan perilaku tidak etis. Chen dan Tang (2006) menemukan bahwa karyawan di Hong Kong dengan love of money yang tinggi bekerja dengan kurang memuaskan dibandingkan rekan-rekan mereka dan hal tersebut dapat menyebabkan perilaku yang tidak etis. Selanjutnya penelitian lainnya yaitu Elias (2010) menemukan bahwa tingkat love of money mahasiswa akuntansi berpengaruh signifikan terhadap persepsi etis mahasiswa tersebut. Nkundabanyanga,dkk (2011) yang meneliti sales personal kosmetik di Uganda menemukan bahwa love of money dari sales personal berpengaruh terhadap perilaku etisnya. Kamayanti dan Widyaningrum (2013) menemukan bahwa love of money mahasiswa akuntansi berpengaruh positif signifikan terhadap persepsi etikanya. Namun Pradanti dan Prastiwi (2014) menemukan bahwa tingkat love of money tidak berpengaruh terhadap persepsi etis mahasiswa akuntansi. Selanjutnya hasil penelitian Sadjiarto dan Foerthiono (2014) menemukan bahwa love of money tidak berpengaruh terhadap persepsi etis mahasiswa akuntansi. 
Dari hasil penelitian yang tidak konsisten peneliti menduga bahwa ada faktor kontigensi yang memengaruhi hubungan antara love of money dan persepsi etis. Menurut Murray (1990) menjelaskan bahwa agar dapat merekonsiliasi hasil yang saling bertentangan diperlukan pendekatan kontigensi untuk mengidentifikasi variabel lain yang bertindak sebagai pemoderasi ataupun pemediasi dalam model riset. Penelitian ini menggunakan kepribadian sebagai variabel pemoderasi karena faktor kepribadian merupakan variabel penting dalam mempengaruhi pola pimikiran dan cara pandang individu terhadap permasalahan tertentu (Lindriansari,dkk 2012).

Kepribadian merupakan salah satu hal penting dalam mewujudkan profesionalisme (Purnamasari, 2006). Tipe kepribadian merupakan sifat kepribadian utama yang dapat memengaruhi perilaku suatu organisasi (Robbins, 2007) dalam Saputri (2015), memengaruhi orientasi umum ke arah pencapaian tujuan, pemilihan alternatif, tindakan terhadap risiko, dan reaksi di bawah tekanan (Kristianti, 2012). Menurut Suryabrata (1995) dalam Kristianti (2012) kepribadian merupakan organinsasi dinamis dan system psikofisik individu yang menentukan tingkah laku dan pemikiran individu secara khas. Kepribadian juga merupakan sesuatu yang terdapat dalam diri individu yang membimbing dan memberi arahan pada tingkah laku individu.

Penelitian ini merupakan pengembangan dari penelitian Lau, dkk (2013) yang melakukan pengujian pengaruh etika uang (money ethics) terhadap perilaku kecurangan pajak (tax evasion) mahasiswa bisnis pada Universitas swasta di Malaysia. Perbedaan penelitian ini dengan penelitian sebelumya yaitu penelitian 
ini lebih menekankan etis dan tidaknya melakukan kecurangan pajak (tax evasion) dengan menambahkan variabel sifat kepribadian sebagai variabel pemoderasi. Penambahan variabel ini didasarkan pada penelitian sebelumnya, yaitu Nasution dan Fitriany (2012) hasil penelitiannya menunjukkan bahwa kepribadian mampu mendeteksi kecurangan, penelitian selanjutnya Farhadi, dkk (2012) hasil penelitianya menunjukkan bahwa kepribadian mampu memprediksi perilaku kecurangan dalam organisasi.

Penelitian ini dilakukan untuk mendeteksi apakah faktor love of money merupakan faktor yang mempengaruhi tax evasion tendency seorang mahasiswa dengan memasukan 2 dimensi dari the big five personality sebagai pemoderasi. The big five personality terdiri dari lima dimensi yaitu opennes to experience, conscientiousness, extraversion, agreeableness, dan neuroticism. Penelitian ini hanya menggunakan dua dimensi yaitu conscientiousness dan agreeableness sebagai variabel pemoderasi. Penelitian Farhadi, dkk (2012) menemukan adanya hubungan yang negatif variabel conscientiousness dan agreeableness pada perilaku kecurangan dalam organisasi. Hal tersebut yang menjadi alasan peneliti untuk memilih dua dimensi dari the big five personality. Added value dalam penelitian ini adalah peneliti menggunakan dua dimensi dari the big five personality yaitu conscientiousness dan agreeablesness sebagai variabel pemoderasi sehingga penelitian ini menjadi relatif baru.

Berdasarkan latar belakang penelitian tersebut, penelitian ini menguji pengaruh love of money pada tax evasion tendency Mahasiswa Magister 
Akuntansi di Universitas Udayana Bali dengan conscientiousness dan agreeablesness sebagai variabel pemoderasi.

Penelitian Elias (2010) menguji hubungan sikap love of money dan persepsi etis. Hasil penelitian menunjukkan hubungan yang negatif sikap love of money dengan etika seseorang. Lau, dkk (2013) menguji pengaruh love of money terhadap kecurangan pajak (tax evasion) dengan intrisic religiosity dan extrinsic religiosity sebagai variabel moderasi. Hasil penelitian menunjukkan bahwa love of money berpengaruh positif terhadap tax evasion, intrisic religiosity memoderasi pengaruh love of money terhadap tax evasion sedangkan extrinsic religiosity tidak memoderasi pengaruh love of money terhadap tax evasion. Hasil yang sama juga dalam penelitian Rosianti, dkk (2014) menguji pengaruh terhadap kecurangan pajak (tax evasion) dengan dengan intrisic religiosity dan extrinsic religiosity sebagai variabel moderasi dengan sampel wajib pajak orang pribadi di Surabaya. Hasil penelitian menunjukkan bahwa love of money berpengaruh positif terhadap tax evasion. Intrisic religiosity memoderasi pengaruh love of money terhadap tax evasion sedangkan extrinsic religiosity tidak memoderasi pengaruh love of money terhadap tax evasion. Hal ini berarti bahwa seseorang dengan love of money tinggi maka persepsi etikanya makin rendah yang memandang tax evasion adalah etis dan sebaliknya seseorang dengan love of money yang rendah maka kecenderungan memandang tax evasion adalah tidak etis. Berdasarkan uraian diatas hipotesis yang diajukan adalah:

$\mathrm{H}_{1}$ : love of money berpengaruh positif pada tax evasion tendency 
Hasil penelitian menunjukkan bahwa kepribadian conscientiousness berhubungan negatif dengan perilaku menyimpang dalam organisasi (Farhadi dkk, 2011) dan berpengaruh pada kinerja individu (Barrick \& Mount, 1991). Hasil berbeda ditunjukkan Robertson, dkk (2000) yang menemukan bahwa kepribadian conscientiousness tidak berpengaruh pada kinerja dan kemampuan untuk mendeteksi kecurangan. Selanjutnya didukung oleh penelitian Jaffar, dkk (2011) yang menemukan bahwa kepribadian conscientiousness tidak mampu memoderasi hubungan penilaian risiko kecurangan dan kemampuan mendeksi kecurangan. Pada karakteristik yang melekat pada kepribadian conscientiousness tersebut, peneliti menduga bahwa individu dengan kepribadian ini memiliki kedisiplinan, bertanggung jawab, sistematik dan berorientasi pada tujuan. Individu dengan kepribdian conscientiousness seseorang memiliki kemampuan untuk mencapai tujuan dengan tidak melakukan perilaku disfungsional (Rustiarini, 2013). Dengan demikian dirumuskan hipotesis penelitian sebagai berikut:

$\mathrm{H}_{2}$ : Conscientiousness memperlemah pengaruh love of money pada Tax Evasion Tendency

Hasil penelitian menunjukkan bahwa kepribadian agreeableness berhubungan negatif dengan perilaku menyimpang dalam organisasi (Farhadi dkk, 2011) dan berpengaruh positif pada kinerja (Skyrme dkk, 2005). Namun berbeda dengan hasil penelitian Jaffar, dkk (2011) yang menemukan bahwa kepribadian agreeableness tidak mampu memoderasi hubungan penilaian risiko kecurangan dan kemampuan mendeksi kecurangan. Karakteristik yang melekat pada kepribadian agreeableness yang identik dengan penciptaan hubungan baik dengan meminimalkan konflik interpersonal, memelihara kerjasama, dan 
melakukan negosiasi untuk menyelesaikan konflik (Graziano dan Tobin, 2002). Individu pada kepribadian agreeableness memiliki kemampuan meminimalkan konflik sehingga uang tidak di pandang sebagai prioritas utama dan memiliki persepsi bahwa tax evasion tendency merupakan tindakan yang tidak etis. Dengan demikian dirumuskan hipotesis penelitian sebagai berikut:

$\mathrm{H}_{3}$ : Agreeableness memperlemah pengaruh love of money pada tax evasion tendency

\section{METODE PENELITIAN}

Rancangan penelitian merupakan petunjuk atau arahan yang sistematis pada proses penelitian (Sanusi, 2014:13). Jenis penelitian ini adalah metode kuantitatif dan desain penelitian ini adalah deskriptif, untuk mendeskripsikan variabel-variabel penelitan dan desain kausalitas untuk meneliti kemungkinan adanya hubungan sebab akibat antar variabel (Kuncoro, 2013: 12-15). Rancangan penelitian ini mencakup tahapan-tahapan penelitian mulai dari latar belakang masalah mengarahkan pada rumusan masalah dan hipotesis penelitian, kemudian dilanjutkan dengan variabel penelitian, yaitu variabel love of money mempengaruhi tax evasion tendency Mahasiswa Magister akuntansi dengan conscientiousness dan agreeableness sebagai variabel pemoderasi. Penelitian ini mengkombinasikan variabel-variabel dalam penelitian sebelumnya dan menambahkan variabel baru yaitu conscientiousness dan agreeableness sebagai variabel pemoderasi serta melakukan melakukan riset dengan dimensi obyek, waktu dan tempat yang berbeda (confirmatory research) dari penelitian-penelitian sebelumnya. 
Instrumen penelitian yang berupa kuesioner digunakan dalam pengumpulan data penelitian. Pengujian mengenai pengaruh love of money pada tax evasion tendency Mahasiswa Magister Akuntansi dengan conscientiousness dan agreeableness sebagai pemoderasi, menggunakan pengujian interaksi yang disebut Moderated Regression Analysis (MRA). Namun sebelum dilakukan pengujian dengan menggunakan Moderated Regression Analysis (MRA), dilakukan pengujian instrumen terlebih dahulu untuk menguji validitas dan reliabilitas kuesioner. Hasil pengujian kemudian dijadikan dasar dalam membuat simpulan. Simpulan juga disusun sesuai dengan masalah penelitian dan hipotesis yang diajukan.

Penelitian dilakukan di Fakultas Ekonomi dan Bisnis Universitas Udayana pada tahun 2016. Adapun alasan dipilihnya lokasi ini karena peneliti ingin mengetahui apakah kadar love of money mempengaruhi tax evasion tendency Mahasiswa Magister Akuntansi dalam pengambilan keputusan dengan conscientiousness dan agreeableness sebagai pemoderasi.

Data yang digunakan dalam mendukung penelitian ini adalah data kualitatif yang dikuantitatifkan. Data kuantitatif adalah data yang berbentuk angka atau data kualitatif yang diangkakan (Sanusi, 2014:104). Data ini diperoleh dari hasil jawaban kuesioner yang disebarkan kemudian diangkakan. Sumber data yang digunakan dalam penelitian ini adalah data primer. Data primer adalah sumber data penelitian yang diperoleh secara langsung dari sumber asli (tidak melalui media perantara). Data primer secara khusus dikumpulkan oleh peneliti untuk menjawab pertanyaan penelitian (Indriantoro dan Supomo, 1999: 146). Data 
primer dalam penelitian ini adalah jawaban responden atas penyebaran kuesioner dengan topik pengaruh love of money pada tax evasion tendency dengan conscientiousness dan agreeableness sebagai variabel pemoderasi.

Data kuantitatif, merupakan data yang berbentuk angka atau data kualitatif yang diangkakan (Sugiyono, 2009). Data kuantitatif dalam penelitian ini yaitu jumlah jawaban kuesioner dari responden. Data kualitatif, merupakan data yang dinyatakan dalam bentuk kata, kalimat, dan gambar (Sugiyono, 2009). Data kualitatif dalam penelitian ini yaitu terkait dengan responden, seperti nama, jenis kelamin, dan jenjang pendidikan strata 1 yang telah ditempuh responden.

Sumber data dalam penelitian ini adalah data primer. Data primer adalah data penelitian yang diperoleh langsung dari sumber asli (tidak melalui perantara) yang secara khusus dikumpulkan oleh peneliti untuk menjawab penelitian (Ruslan, 2003:282). Data primer dalam penelitian ini, yaitu jawaban responden atas pertanyaan-pertanyaan dalam kuisioner penelitian.

Populasi adalah wilayah generalisasi yang terdiri atas objek/subjek yang mempunyai kualitas dan karakteristik tertentu yang ditetapkan oleh peneliti untuk dipelajari dan kemudian ditarik kesimpulannya (Sugiyono,2015:167). Populasi dalam penelitian ini adalah semua Mahasiswa Magister Akuntansi Universitas Udayana tahun 2015/2016 sejumlah 154 orang dengan rincian pada tabel 1 .

Tabel 1.

\begin{tabular}{ccc}
\multicolumn{3}{c}{ Mahasiswa Magister Akuntansi tahun 2015/2016 } \\
\hline No & Keterangan & Jumlah \\
\hline 1 & Semester 1 & 25 orang \\
2 & Semester 2 & 44 orang \\
3 & Semester 3 & 38 orang \\
4 & Semester 4 & 47 orang \\
\hline
\end{tabular}

Sumber: Bagian Akademik Maksi (2016) 
Sampel adalah bagian dari jumlah dan karakteristik yang dimiliki oleh populasi tersebut (Sugiyono, 2015:168). Pengambilan sampel dalam penelitian ini menggunakan metode non probability dengan teknik purposive sampling. Purposive sampling adalah teknik pengambilan sampel sumber data dengan pertimbangan tertentu (Sugiyono, 2015: 176). Jumlah sampel pada penelitian ini sebanyak 85 orang yang terdiri dari semester 3 sebanyak 38 dan semester 4 sebanyak 47 orang.

Variabel bebas merupakan variabel yang memengaruhi atau menjadi sebab perubahannya atau timbulnya variabel terikat (Sugiyono, 2015:82). Variabel bebas dalam penelitian ini adalah love of money $\left(\mathrm{X}_{1}\right)$. Variabel terikat merupakan variabel yang dipengaruhi atau yang menjadi akibat, karena adanya variabel bebas (Sugiyono, 2015:82). Variabel terikat dalam penelitian ini adalah tax evasion tendency $(\mathrm{Y})$. Variabel moderasi adalah variabel yang mempengaruhi (memperkuat dan memperlemah) hubungan antara variabel bebas dengan variabel (Sugiyono, 2015: 82). Dalam penelitian ini yang menjadi variabel moderasi adalah conscientiousness $\left(\mathrm{X}_{2}\right)$ dan agreeableness $\left(\mathrm{X}_{3}\right)$.

Pretest digunakan untuk mengetahui kondisi awal atau kemampuan awal subjek sebelum diberi tindakan tertentu (Sugiyono, 2015:243). Pretest digunakan untuk meningkatkan validitas internal. Beberapa perubahan terhadap desain desain awal kuesioner kemungkinan dilakukan dengan masukan dari partisipan yang sesuai dengan tujuan penelitian. Pretest dilakukan terhadap mahasiswa Magister Akuntansi Star BPKP sebanyak 30 orang pada Universitas Udayana. 
Regresi sederhana didasarkan pada hubungan fungsional ataupun kausal satu variabel independen dengan satu variabel dependen (Sugiyono, 2010:270). Persamaan umum regresi linear sederhana adalah:

$$
\mathrm{Y}=\alpha+\beta \mathrm{X}+\varepsilon
$$

Keterangan:

$\mathrm{Y}^{\prime}=$ tax evasion tendency

$\alpha=$ Konstanta

$\beta=$ Koefisien regresi

$\mathrm{X}=$ love of money

Pengujian yang dilakukan untuk mengetahui apakah suatu variabel merupakan variabel pemoderasi adalah dengan melakukan uji interaksi Moderated Regression Analysis (MRA). Variabel moderasi adalah variabel independen yang akan memperkuat atau memperlemah hubungan antara variabel independen lainnya terhadap variabel dependen. Penelitian ini menggunakan uji interaksi MRA dengan persamaan regresi:

$$
\mathrm{Y}=a+\beta_{1} \mathrm{X}_{1}+\beta_{2} \mathrm{X}_{2}+\beta_{3} \mathrm{X}_{3}+\beta_{4} \mathrm{X}_{1} \cdot \mathrm{X}_{2}+\beta_{5} \mathrm{X}_{1} \cdot \mathrm{X}_{3}+\varepsilon
$$

Keterangan:

$$
\begin{array}{ll}
\mathrm{Y} & =\text { Tax Evasion Tendency } \\
a & =\text { Konstanta } \\
\beta & =\text { Koefisien Regresi } \\
\mathrm{X}_{1} & =\text { Love of Money } \\
\mathrm{X}_{2} & =\text { Conscientiousnes } \\
\mathrm{X}_{3} & =\text { Agreeableness } \\
\varepsilon & =\text { error }
\end{array}
$$

Pengujian interaksi, jika koefisien regresi $\beta_{2}$ dan $\beta_{3}$ tidak signifikan, sedangkan $\beta_{4}$ dan $\beta_{5}$ signifikan ini berarti bahwa variabel moderasi yaitu Conscientiousnes dan Agreeableness merupakan variabel pure moderator (moderator murni). Hasil pengujian $\beta_{2}, \beta_{3}, \beta_{4}$ dan $\beta_{5}$ signifikan ini berarti bahwa Conscientiousnes dan Agreeableness merupakan variabel quasi moderator. Quasi 
moderator merupakan variabel yang memoderasi hubungan antara variabel independen dan variabel dependen yang sekaligus menjadi variabel independen. Uji interaksi yang menunjukkan hasil $\beta_{2}$ dan $\beta_{3}$ signifikan sedangkan $\beta_{4}$ dan $\beta_{5}$ tidak signifikan ini berarti bahwa variabel Conscientiousnes dan Agreeableness merupakan variabel prediktor moderator artinya 2 variabel moderasi ini hanya berperan sebagai variabel prediktor (independen) dalam model yang dibentuk. Hasil pengujian $\beta_{2}, \beta_{3}, \beta_{4}$ dan $\beta_{5}$ tidak signifikan berarti bahwa variabel moderasi dikatakan sebagai homogolizer moderator artinya variabel Conscientiousnes dan Agreeableness berpotensi menjadi variabel moderasi (Utama, 2016: 150).

\section{HASIL DAN PEMBAHASAN}

Statistik deskriptif disajikan dalam memberikan informasi tentang karakteristik variabel penelitian. Ringkasan hasil statistik deskriptif dapat dilihat pada tabel 2.

Tabel 2.

Statistik Deskriptif Data Uji

\begin{tabular}{lccccc}
\hline \multicolumn{1}{c}{ Variabel } & N & Min & Max & Mean & Std. Deviation \\
\hline Love Of Money $\left(\mathrm{X}_{1}\right)$ & 82 & 14,00 & 54,69 & 27,18 & 10,97 \\
Conscientiousness $\left(\mathrm{X}_{2}\right)$ & 82 & 7,00 & 27,71 & 20,57 & 5,58 \\
Agreeableness $\left(\mathrm{X}_{3}\right)$ & 82 & 8,00 & 33,53 & 15,79 & 5,72 \\
Tax Evasion $(\mathrm{Y})$ & 82 & 14,00 & 55,76 & 28,16 & 11,06 \\
Valid N (listwise) & 82 & & & &
\end{tabular}

Sumber: data primer diolah, (2016)

Tabel 2 menunjukkan jumlah responden $(\mathrm{N})$ adalah 82 orang mahasiswa.

Nilai minimum love of money 14,00, nilai maksimum 54,69 dengan nilai rata-rata 27,18 dan std. deviasi 10,97. Range penyebaran data hasil jawaban responden dapat dilihat pada tabel 3 . 
Tabel 3.

Klasifikasi Variabel Love of Money

\begin{tabular}{ccc}
\hline Rentang Klasifikasi & Klasifikasi & $\begin{array}{c}\text { Rata-rata Data } \\
\text { Responden }\end{array}$ \\
\hline $14,00 \leq$ Love of Money $<22,13$ & Sangat Rendah & \\
$22,13 \leq$ Love of Money $<30,27$ & Rendah & 27,18 \\
$30,27 \leq$ Love of Money $<38,41$ & Cukup & \\
$38,41 \leq$ Love of Money $<46,55$ & Tinggi & \\
$46,55 \leq$ Love of Money $<54,69$ & Sanggat Tinggi & \\
\hline Sumber: data primer diolah, $(2016)$ &
\end{tabular}

Hasil rata-rata jawaban responden sebesar 27,18 yang sebaran datanya cenderung ke kiri menunjukkan klasifikasi jawaban responden dalam penelitian ini memiliki love of money yang merata. Artinya responden menilai uang sebagai alat untuk memenuhi kebutuhan dan responden tidak mempunyai perasaan yang mendewakan uang.

Tabel 2 menunjukkan jumlah responden $(\mathrm{N})$ adalah 82 orang mahasiswa. Variabel conscientiousness nilai minimum 7,00 nilai maksimum 27,71 nilai rata-rata 20,57 dan std. deviasi 5,57. Range penyebaran data hasil jawaban responden dapat dilihat pada tabel 4.

Tabel 4.

Klasifikasi Variabel Conscientiousness

\begin{tabular}{ccc}
\hline Rentang Klasifikasi & Klasifikasi & $\begin{array}{c}\text { Rata-rata Data } \\
\text { Responden }\end{array}$ \\
\hline $7,00 \leq$ Conscientiousness $<11,14$ & Sangat Rendah & \\
$11,14 \leq$ Conscientiousness $<15,28$ & Rendah & \\
$15,28 \leq$ Conscientiousness $<19,42$ & Cukup & 20,57 \\
$19,42 \leq$ Conscientiousness $<23,56$ & Tinggi & \\
$23,56 \leq$ Conscientiousness $<27,71$ & Sanggat Tinggi & \\
\hline
\end{tabular}

Sumber: data primer diolah, (2016)

Hasil rata-rata jawaban responden sebesar 20,57 yang sebaran datanya cenderung kekanan menunjukkan klasifikasi jawaban responden dalam penelitian ini memiliki kepribadian conscientiousness yang tinggi.

Tabel 2. menunjukkan jumlah responden $(\mathrm{N})$ adalah 82 orang mahasiswa. Variabel agreeableness nilai minimum 8,00, nilai maksimum 33,53, nilai rata-rata 
15,79 dengan std.deviasi 5,72. Range penyebaran data hasil jawaban responden dapat dilihat pada tabel 5 .

Tabel 5.

Klasifikasi Variabel Agreeableness

\begin{tabular}{ccc}
\hline Rentang Klasifikasi & Klasifikasi & $\begin{array}{c}\text { Rata-rata Data } \\
\text { Responden }\end{array}$ \\
\hline $8,00 \leq$ Agreeableness $<13,11$ & Sangat Rendah & 15,79 \\
$13,11 \leq$ Agreeableness $<18,21$ & Rendah & \\
$18,21 \leq$ Agreeableness $<23,31$ & Cukup & \\
$19,42 \leq$ Agreeablenes $<28,41$ & Tinggi & \\
$28,41 \leq$ Agreeablenes $<33,53$ & Sanggat Tinggi & \\
\hline Sumber: data primer diolah, (2016) &
\end{tabular}

Hasil rata-rata jawaban responden sebesar 15,79 yang sebaran datanya cenderung ke kiri menunjukkan klasifikasi jawaban responden dalam penelitian ini memiliki kepribadian agreeableness yang rendah.

Tabel 2 menunjukkan jumlah responden $(\mathrm{N})$ adalah 82 orang mahasiswa.

Vaiabel tax evasion tendency nilai minimum 14,00, nilai maksimum 55,76, nilai rata-rata 28,16 dengan std.deviasi 11,06. Range penyebaran data hasil jawaban responden dapat dilihat pada tabel 6 .

Tabel 6.

Klasifikasi Variabel Tax Evasion Tendency

\begin{tabular}{ccc}
\hline Rentang Klasifikasi & Klasifikasi & $\begin{array}{c}\text { Rata-rata Data } \\
\text { Responden }\end{array}$ \\
\hline $14,00 \leq$ Tax Evasion $<22,35$ & Sangat tidak Etis & \\
$22,35 \leq$ Tax Evasion $<30,70$ & Tidak Etis & 28,16 \\
$30,70 \leq$ Tax Evasion $<39,05$ & Cukup & \\
$39,05 \leq$ Tax Evasion $<47,40$ & Etis & \\
$47,40 \leq$ Tax Evasion $<55,76$ & Sanggat Etis & \\
\hline Sumber: data primer diolah, (2016) & &
\end{tabular}

Hasil rata-rata jawaban responden sebesar 28,16 yang sebaran datanya cenderung ke kanan menunjukkan responden dalam penelitian melihat tax evasion dalam pandangan tidak etis.

Uji normalitas bertujuan untuk menguji apakah dalam model regresi, variabel terikat dan variabel bebas keduanya memiliki distribusi normal atau tidak 
normal. Pada penelitian ini uji normalitas dilakukan dengan menggunakan nilai Kolmogorov-Smirnov. Suatu data dikatakan memiliki distribusi normal jika signifikansi atau nilai Asymp.Sig.(2-tailed) dari Kolmogorov-Smirnov lebih besar dari 0,05. Hasil uji normalitas disajikan pada tabel 7.

Tabel 7.

Hasil Uji Normalitas

\begin{tabular}{llll}
\hline No & Model & $\begin{array}{l}\text { Kolmogorov- } \\
\text { Sminorv } \mathbf{Z}\end{array}$ & $\begin{array}{l}\text { Asymp.Sig.(2- } \\
\text { tailed) }\end{array}$ \\
\hline 1 & $Y=\alpha+\beta_{1} X_{1}$ & 0,066 & 0,200 \\
2 & $Y=\alpha+\beta_{1} X_{1}+\beta_{2} X_{2}+\beta_{3} X_{3}+\beta_{3} X_{1} X_{3}+\beta_{3} X_{2} X_{3}+\varepsilon$ & 0,084 & 0,200 \\
\hline \multicolumn{2}{c}{ Sumber: data primer diolah, (2016) }
\end{tabular}

Hasil uji normalitas pada tabel 7 menunjukkan nilai Asymp.Sig.(2-tailed) untuk model regresi sederhana dan regresi moderasi sebesar 0,200 (lebih besar dari 0,05). Hal ini mempunyai arti bahwa variabel-variabel yang digunakan dalam penelitian sudah terdistribusi normal.

Uji multikolinearitas bertujuan untuk menguji apakah model regresi ditemukan adanya korelasi antar variabel bebas. Model regresi yang baik adalah tidak terjadi korelasi diantara variabel bebas. Multikolinearitas terjadi jika nilai Tolerance $<0,10$ atau nilai VIF $>10$. Hasil uji multikolinearitas disajikan pada tabel 8 .

Tabel 8.

Hasil Uji Multikolinearitas

\begin{tabular}{lcc}
\hline Variabel & Tolerence & VIF \\
& & \\
\hline Love Of Money $\left(\mathrm{X}_{1}\right)$ & 0,727 & 1,376 \\
Conscientiousness $\left(\mathrm{X}_{2}\right)$ & 0,714 & 1,401 \\
Agreeableness $\left(\mathrm{X}_{3}\right)$ & 0,701 & 1,427 \\
\hline Sumber: data primer diolah $(2016)$ &
\end{tabular}

Sumber: data primer diolah, (2016)

Tabel 8 menunjukkan bahwa variabel love of money $\left(\mathrm{X}_{1}\right)$

conscientiousness $\left(\mathrm{X}_{2}\right)$ dan agreeableness $\left(\mathrm{X}_{3}\right)$ memiliki nilai tolerence $>0,10$ 
dan nilai VIF < 10. Ini menunjukkan bahwa tidak terdapat multikolinearitas dalam regresi.

Uji heteroskedasitas digunakan untuk melihat apakah terjadi ketidaksamaan varians dari residual satu pengamatan ke pengamatan yang lain. Model regresi yang memenuhi syarat adalah dimana terdapat kesamaan varians dari residual satu pengamatan ke pengamatan yang lain. Dalam penelitian ini, model statistik yang digunakan untuk menentukan model regresi terbebas dari masalah heteroskedasitas yaitu uji Glejser. Hasil uji heteroskedasitas disajikan pada tabel 9.

Tabel 9.

Hasil Uji Heteroskedasitas

\begin{tabular}{ll}
\hline Variabel & Sig $\mathbf{t}$ \\
\hline $\mathrm{X}_{1}$ & 0,125 \\
$\mathrm{X}_{2}$ & 0,191 \\
$\mathrm{X}_{3}$ & 0,377 \\
$\mathrm{X}_{1} \cdot \mathrm{X}_{2}$ & 0,152 \\
$\mathrm{X}_{2} \cdot \mathrm{X}_{3}$ & 0,579 \\
\hline
\end{tabular}

Sumber: data primer diolah, (2016)

Keterangan:

$\mathrm{X}_{1} \quad=$ Love of Money

$\mathrm{X}_{2}=$ Conscientiousness

$\mathrm{X}_{3}=$ Agreeableness

$\mathrm{X}_{1} . \mathrm{X}_{2}=$ interaksi Love of Money dengan Conscientiousness

$\mathrm{X}_{2} . \mathrm{X}_{3}=$ interaksi Love of Money dengan Agreeableness

Tabel 9 menunjukkan bahwa nilai sig dari masing-masing variabel adalah diatas 0,05 . Jadi dapat disimpulkan bahwa pada model regresi tidak ditemukan gejala heteroskedasitas. 
Tabel 10.

Hasil Regresi Sederhana

\begin{tabular}{|c|c|c|c|c|c|}
\hline \multirow[t]{2}{*}{ Variabel } & \multicolumn{2}{|c|}{$\begin{array}{l}\text { Undstandardized } \\
\text { Coefficients }\end{array}$} & \multirow{2}{*}{$\begin{array}{c}\text { Standardized } \\
\text { Coefficients } \\
\text { Beta }\end{array}$} & \multirow[t]{2}{*}{$\mathbf{t}$} & \multirow[t]{2}{*}{ Sig. } \\
\hline & B & Std. Error & & & \\
\hline (Constant) & 13,466 & 2,784 & & 4,837 & 0,000 \\
\hline Love of Money $\left(\mathrm{X}_{1}\right)$ & 0,541 & 0,095 & 0,537 & 5,689 & 0,000 \\
\hline
\end{tabular}

Sumber: data primer diolah, (2016)

$\mathrm{Y}=13,466+0,541 \mathrm{X}_{1}+\varepsilon$

Dimana:

$$
\begin{array}{ll}
\mathrm{Y} & =\text { Tax Evasion } \\
\mathrm{X}_{1} & =\text { Love of Money } \\
\varepsilon & =\text { error }
\end{array}
$$

Nilai konstanta atau $\alpha=13,466$, artinya apabila variabel love of money tidak ada atau sama dengan 0 (nol), maka besarnya tax evasion adalah 13,466 satuan. Nilai koefisien regresi love of money $\left(\mathrm{X}_{1}\right)$ sebesar 0,541 artinya apabila variabel love of money meningkat sebesar satu satuan maka variabel tax evasion tendency meningkat sebesar 0,541 dengan asumsi variabel lainnya konstan.

Uji kelayakan model (uji F) dimaksudkan dalam rangka mengetahui apakah dalam penelitian ini model yang digunakan layak untuk digunakan atau tidak sebagai alat analisis untuk menguji pengaruh variabel independen pada variabel dependennya. Hasil uji kelayakan model disajikan pada tabel 11.

Tabel 11.

Hasil Uji Kelayakan Model

\begin{tabular}{lllrrrr}
\hline Model & & $\begin{array}{l}\text { Sum of } \\
\text { Squares }\end{array}$ & Df & \multicolumn{1}{c}{$\begin{array}{c}\text { Mean } \\
\text { Square }\end{array}$} & F & Sig \\
\hline 1 & Regression & 4998,487 & 5 & 999,697 & 15,485 & $0,000^{\mathrm{b}}$ \\
& Residual & 4906,426 & 76 & 64,558 & & \\
& Total & 9904,913 & 81 & & & \\
\hline
\end{tabular}

Sumber: data primer diolah, (2016) 
Berdasarkan tabel 11 dapat diketahui bahwa uji $\mathrm{F}$ menghasilkan nilai

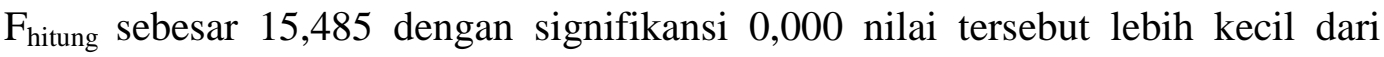
tingkat signifikansi yang ditetapkan $\alpha=0,05$ ( $\alpha=5$ persen).

Koefisien determinasi menggambarkan sejauhmana variabel independen dalam model, mampu menjelaskan variabilitas dependennya (Ghozali, 2013). Indikator koefisien determinasi yang digunakan dalam penelitian ini adalah Adjusted $R_{2}$. Besarnya koefisien determinasi Adjusted $R_{2}$ ditunjukkan pada tabel 12.

Tabel 12.

Koefisien Determinasi

\begin{tabular}{lcllll}
\hline Model & R & R Square & $\begin{array}{l}\text { Adjusted } \\
\text { Square }\end{array}$ & $\begin{array}{l}\text { Std. Error of } \\
\text { the Estimate }\end{array}$ \\
\hline 1 &, $710^{\mathrm{a}}$ &, 505 &, 472 & 8,03481 \\
\hline Sumber: data primer diolah, (2016) & & & & \\
& & & \\
& Berdasarkan tabel 12 dapat diketahui & bahwa koefisien determinasi
\end{tabular}

Adjusted $R_{2}$ adalah sebesar 0,472. Ini berarti bahwa 47,2\% variasi perubahan variabel tax evasion dapat dijelaskan oleh variabel love of money yang dimoderasi oleh conscientiousness dan agreeableness. Sedangkan 52,8\% dipengaruhi oleh variabel lain diluar model.

Model pengujian statistik yang digunakan dalam penelitian ini adalah analisis regresi. Analisis regresi digunakan untuk melihat ketergantungan variabel dependen dengan satu atau lebih variabel independen. Tujuannya untuk mengestimasi nilai rata-rata variabel dependen berdasarkan nilai variabel independen yang diketahui. Penelitian ini menggunakan regresi moderasi interaksi. Hasil analisis regresi moderasi dengan interaksi disajikan pada tabel 13. 
Tabel 13.

Hasil Analisis Regresi Moderasi

\begin{tabular}{lcrcrrr}
\hline \multicolumn{1}{c}{ Variabel } & \multicolumn{2}{c}{$\begin{array}{c}\text { Undstandardized } \\
\text { Coefficients } \\
\end{array}$} & \multicolumn{1}{c}{$\begin{array}{c}\text { Std. Error } \\
\text { B }\end{array}$} & $\begin{array}{c}\text { Standardized } \\
\text { Coefficients } \\
\text { Beta }\end{array}$ & t & Sig. \\
\hline (Constant) & & 16,676 & 8,484 & & 1,966 & 0,000 \\
Love of Money & $\left(\mathrm{X}_{1}\right)$ & 0,235 & 0,202 & 0,234 & 1,163 & 0,248 \\
Conscientiousness & $\left(\mathrm{X}_{2}\right)$ & $-0,502$ & 0,296 & $-0,253$ & $-1,695$ & 0,094 \\
Agreeableness & $\left(\mathrm{X}_{3}\right)$ & 1,639 & 0,349 & 0,848 & 4,692 & 0,000 \\
$\mathrm{X}_{1} \cdot \mathrm{X}_{2}$ & & 0,005 & 0,005 & 0,148 & 0,880 & 0,382 \\
$\mathrm{X}_{1} \cdot \mathrm{X}_{3}$ & $-0,030$ & 0,011 & $-0,466$ & $-2,804$ & 0,006 \\
\hline
\end{tabular}

Sumber: data primer diolah, (2016)

$Y=16,676+0,235 X_{1}-0,502 X_{2}+1,639 X_{3}+0,005 X_{1} . X_{2}-0,030 X_{1 .} X_{3}+\varepsilon$

Keterangan:

$\mathrm{Y} \quad=$ Tax Evasion Tendency

$\mathrm{X}_{1} \quad=$ Love of Money

$\mathrm{X}_{2} \quad=$ Conscientiousness

$\mathrm{X}_{3}=$ Agreeableness

$\mathrm{X}_{1} \cdot \mathrm{X}_{2}=$ interaksi Love of Money dengan Conscientiousness

$\mathrm{X}_{1} . \mathrm{X}_{3}=$ interaksi Love of Money dengan Agreeableness

$\varepsilon \quad=$ error

Nilai koefisien interaksi love of money dengan conscientiousness $\left(\mathrm{X}_{1} \mathrm{X}_{2}\right)$ sebesar 0,005 dengan signifikansi 0,382 lebih besar dari tingkat signifikansi yang ditetapkan $(\alpha=0,05)$ artinya hipotesis di tolak dan variabel conscientiousness tidak memoderasi pengaruh love of money pada tax evasion tendency.

Nilai koefisien interaksi love of money dengan agreeableness $\left(\mathrm{X}_{1} \mathrm{X}_{3}\right)$ sebesar -0,030 dengan signifikansi 0,006 lebih kecil dari tingkat signifikansi yang ditetapkan $(\alpha=0,05)$ hipotesis di terima dan variabel agreeableness memoderasi pengaruh love of money pada tax evasion tendency.

Berdasarkan tabel 10 diperoleh hasil uji regresi sederhana dan tabel 13 regresi moderasi menggunakan metode interaksi, dapat diketahui informasi terhadap uji hipotesis sebagai berikut: 
Nilai koefisien regresi love of money sebesar 0,541 pada tabel 13 dengan nilai signifikansi sebesar 0,000 , lebih kecil dari tingkat signifikansi yang ditetapkan $(\alpha=0,05)$ artinya bahwa variabel love of money berpengaruh positif pada variabel tax evasion tendency. Penelitian ini membuktikan bahwa hipotesis 1 diterima, yaitu love of money berpengaruh positif pada variabel tax evasion tendency.

Nilai koefisien regresi moderasi $\left(\mathrm{X}_{1} \mathrm{X}_{2}\right)$ sebesar 0,005 pada tabel 13 dengan nilai signifikansi sebesar 0,382 lebih besar dari tingkat signifikansi yang ditetapkan $(\alpha=0,05)$ artinya bahwa variabel conscientiousness tidak memoderasi pengaruh love of money pada tax evasion tendency, sehingga hasil ini menolak hipotesis 2. Berdasarkan tabel 13 diperoleh informasi bahwa variabel conscientiousness $\left(\mathrm{X}_{2}\right)$ merupakan jenis variabel homogolizer moderator (moderasi potensial), hal ini ditunjukkan bahwa variabel conscientiousness tidak mempunyai pengaruh langsung pada tax evasion tendency dan tidak berinteraksi dengan variabel love of money.

Nilai koefisien regresi moderasi $\left(\mathrm{X}_{1} \mathrm{X}_{3}\right)$ sebesar $-0,030$ pada tabel 13 dengan nilai signifikansi sebesar 0,006 lebih kecil dari tingkat signifikansi yang ditetapkan $(\alpha=0,05)$ artinya bahwa variabel agreeableness memoderasi pengaruh love of money pada variabel tax evasion tendency, sehingga hipotesis 3 diterima. Berdasarkan tabel 13 diperoleh informasi bahwa variabel agreeableness $\left(\mathrm{X}_{3}\right)$ merupakan jenis variabel quasi moderator (moderasi semu), artinya variabel agreeableness merupakan variabel yang memoderasi hubungan antara love of 
money dengan tax evasion tendency yang sekaligus bisa menjadi variabel independen.

Hasil analisis terhadap hipotesis pertama yang merumuskan bahwa love of money berpengaruh positif pada tax evasion tendency, menunjukkan bahwa hipotesis pertama dapat diterima. Hasil yang di peroleh adalah love of money berpengaruh positif pada tax evasion tendency. Hasil tersebut menunjukkan bahwa semakin tinggi love of money individu maka cenderung melakukan tax evasion dan sebaliknya semakin rendah love of money individu maka cenderung tidak melakukan tax evasion. Tang dan Chiu (2003) menjelaskan bahwa love of money sangat terkait dengan konsep ketamakan yang merupakan karakter seseorang dalam mendewakan uang. Basri (2014) mengartikan love of money sebagai sikap seseorang yang mencintai uang. Individu dengan love of money yang tinggi akan memprioritaskan uang dalam aspek kehidupannya sehingga menjadi kurang peka dan kurang etis dibandingkan dengan individu dengan love of money yang rendah.

Berdasarkan tax morale theory yang menyebutkan bahwa faktor sifat individu mempengaruhi moral pajak. Sifat individu berupa love of money dari Mahasiswa Magister Akuntansi dapat mempengaruhi moral pajaknya. Artinya love of money yang tinggi dapat mempengaruhi moral pajak seseorang yaitu melakukan tax evasion dibandingkan dengan seseorang dengan love of money yang rendah akan kecenderungan untuk tidak melakukan tax evasion. Hasil ini menunjukkan bahwa love of money Mahasiswa Magister Akuntansi berpengaruh positif pada tax evasion tendency. Temuan ini mendukung penelitian Lau, Choe 
dan Tan (2013) yang menunjukkan hubungan positif antara love of money dan tax evasion. Hasil ini juga mendukung penelitian Rosianti dan Mangoting (2014) yang menunjukkan hubungan hubungan positif antara love of money dan tax evasion.

Hasil analisis terhadap hipotesis kedua yang merumuskan bahwa conscientiousness memperlemah pengaruh love of money pada tax evasion tendency, menunjukkan bahwa hipotesis kedua tidak dapat diterima. Hasil yang diperoleh adalah conscientiousness tidak memoderasi pengaruh love of money pada tax evasion tendency. Hasil tersebut menunjukkan bahwa individu dengan kepribadian conscientiousness tidak memoderasi pengaruh love of money pada tax evasion tendency. Hasil ini sejalan dengan teori kepribadian yang menyatakan bahwa sekumpulan trait psikologis dan mekanisme didalam individu yang diorganisasikan, relatif bertahan yang mempengaruhi interaksi dan adaptasi individu didalam lingkungan. Hasil penelitian ini juga didukung dengan tax morale theory yang menyebutkan bahwa dalam moral pajak yang diukur adalah sifat dan pendirian individu. Sifat dan pendirian individu ini menekankan pada kesadaran dalam melaksanakan kewajiban perpajakannya. Hasil penelitian menunjukkan bahwa Mahasiswa Magister Akuntansi dengan kepribadian conscientiousness tidak memoderasi pengaruh love of money pada tax evasion tendency. Temuan ini mendukung penelitian Jaffar, dkk (2012) yang menunjukkan bahwa tidak ada efek interaksi seseorang dengan kepribadian conscientiousness dengan tindakan kecurangan. 
Marce Sherly Kase, H. Bambang Suprasto dan Maria M. Ratna Sari. Conscientiousness......

Hasil analisis terhadap hipotesis ketiga yang merumuskan bahwa agreeableness memperlemah pengaruh love of money pada tax evasion tendency, menunjukkan bahwa hipotesis ketiga dapat diterima. Hasil yang diperoleh adalah agreeableness memperlemah pengaruh love of money pada tax evasion tendency. Hasil tersebut menunjukkan bahwa individu dengan kepribadian agreeableness memperlemah pengaruh love of money pada tax evasion tendency. Hasil ini sejalan dengan teori kepribadian yang di kemukakan oleh Barrick \& Ryan (2003) yang menyebutkan bahwa sistem psikopysikal didalam individu menentukan penyesuaian diri individu secara unik terhadap lingkungan. Hasil penelitian ini didukung dengan tax morale theory yang menyebutkan bahwa faktor sifat individu mempengaruhi moral pajak. Karakteristik agreeableness memiliki kemampuan dalam menyesuaian diri dan dapat dipercaya artinya tidak melakukan hal-hal yang melanggar aturan yang telah ditetapkan yaitu memiliki kesadaran untuk melaksanakan kewajiban perpajakan dan cenderung untuk menghindari tax evasion. Hasil penelitian ini menunjukkan bahwa Mahasiswa Magister Akuntansi dengan kepribadian agreeableness memperlemah pengaruh love of money pada tax evasion tendency. Temuan ini mendukung penelitian Farhadi, dkk (2012) yang menunjukkan bahwa individu dengan kepribadian agreeableness cenderung tidak melakukan tindakan kecurangan. 


\section{SIMPULAN DAN SARAN}

Berdasarkan hasil analisis dan pembahasan yang telah dilakukan, maka dapat disimpulkan bahwa love of money berpengaruh positif pada tax evasion tendency. Hasil tersebut mendukung hipotesis pertama yang merumuskan bahwa love of money berpengaruh positif pada tax evasion tendency. Hal ini bermakna jika love of money tinggi maka kecenderungan melakukan tax evasion dan sebaliknya jika love of money rendah maka kecenderungan tidak melakukan tax evasion. Conscientiousness tidak memoderasi pengaruh love of money pada tax evasion tendency. Hasil tersebut menolak hipotesis kedua yang merumuskan bahwa conscientiousness memperlemah pengaruh love of money pada tax evasion tendency. Agreeableness memperlemah pengaruh love of money pada tax evasion tendency. Hasil tersebut mendukung hipotesis ketiga yang merumuskan bahwa agreeableness memperlemah pengaruh love of money pada tax evasion tendency. Hal ini bermakna individu dengan kepribadian agreeableness yang memiliki kemampuan dalam menimimalkan konflik dan dapat di percaya maka cenderung tidak melakukan tax evasion. Hasil penelitian menunjukkan bahwa variabel agreeableness merupakan quasi moderator.

Berdasarkan pembahasan dan telaah jawaban responden dapat disarankan bahwa Program Magister Akuntansi disarankan agar memasukan pemahaman yang lebih mendalam mengenai love of money pada mata kuliah etika bisnis dan profesi. Hasil nilai Adjusted $R^{2}$ sebesar 0,472 yang berarti variabilitas variabel tax evasion dapat dijelaskan oleh love of money,conscientiousnes, dan agreeableness sebesar $47,2 \%$ sedangkan sisanya sebesar $52,8 \%$ dijelaskan oleh variabel lain 
diluar model. Hal ini membuka peluang bagi peneliti selanjutnya untuk menambah variabel lain seperti gender, demographic, intrinsic religiosity dan extrinsic religiosity.

\section{REFERENSI}

Anwar,Y. dan Amarullah, F. 2006. Perbedaan Persepsi Mahasiswa Akuntansi terhadap Etika Penyusunan Laporan Keuangan. Jurnal Akuntansi dan Keuangan Indonesia. 3 (1) : pp. 107-126.

Aziz, T.I. dan Taman, A. 2015. Pengaruh Love of Money dan Machiavellian terhadap Persepsi Etis Mahasiswa Akuntansi. Jurnal Nominal. 4 (2) : pp. 31-44.

Barrick, M.B. and Mount, M.K. 1991. The Big-Five Personality Dimension and Job Performance: A Meta-Analysis. Personnel Pscychology. 44 (1) : pp.1-26.

Barrick, M.R. \& Ryan, A.M. 2003. Personality and work: Reconsidering the role of personality in organization. San Francisco, CA: Jossey-Bass.

Basri, Y.M. 2014. Efek Moderasi Religuisitas dan Gender terhadap Hubungan Etika Uang (Money Ethics) dan Kecurangan Pajak (Tax Evasion). Simposium Nasional Akuntnsi XVII. Lombok 24-27 September.

Chrismastuti, A.A dan Purnamasari, V. 2004. Hubungan Sifat Machiavellian, Pembelajaran Etika dalam Mata Kuliah Etika, dan Sikap Etis Akuntan: Suatu Analisis Perilaku Etis Akuntan dan Mahasiswa Akuntansi di Semarang. Simposium Nasional Akuntansi VII. Denpasar 2-3 Desember.

Clikeman, P. M dan Henning, S. L. 2000. The Socialization of Undergraduate Accounting Students. Issues in Accounting Education 15 (1) : pp. 1-15

Elias dan Farag. 2010. The Relationship between Accounting Student's Love of Money and Their Ethical Perception. Managerial Auditing Journal. 25 (3) : pp. 269-281.

Farhadi, H.; Fatima, O.; Nasir, R.; Shahrazad, W. 2012. Agreeableness and Conscientiousness as Antecedents of Deviant Behavior in Workplace. Asian Social Science. 8 (9) : pp. 2-7.

Ghozali, Imam. 2013. Aplikasi Analisis Multivariate dengan Program SPSS. Edisi ke 7 Semarang: Badan Penerbit Universitas Diponegoro.

Graziano, W. G. and Tobin, R. M. 2002. Agreeableness: Dimension of Personality of Social Desirability Artifact?. Journal of Personality. 70 (5) : pp. 695-728. 
Hastuti, E.C. 2007. Perilaku Etis Mahasiswa dan Dosen ditinjau dari Faktor Individual Gender dan Locus Of Control. Jurnal Riset Ekonomi dan Bisnis. 7 (1) : pp. 58-73.

Husein, M.F. 2004. Keterkaitan Faktor-Faktor Organisasional, Individual, Konflik Peran, Perilaku Etis dan Kepuasan Kerja Akuntan Manajemen. Makalah Simposium Dwi Tahunan J-AME-R. Yogyakarta.

Indriantoro, Nur dan Supomo Bambang. 1999. Metodologi Penelitian Bisnis untuk Akuntansi \& Manajemen. Edisi Pertama. Yogyakarta: BPFE

Jaffar, N., Salleh, A., Iskandar.T.M., and Haron,H. 2011. Fraud Risk Assessment and Detection of Fraud: The Moderating Effect of Personality. International Journal of Business and Management. 6 (7) : pp. 40-50.

Kamayanti, A. dan Widyaningrum, A. 2013. Determinan Persepsi Etika Mahasiswa Akuntansi dengan Love of Money sebagai Variabel Intervening. Jurnal Ilmiah Mahasiswa FEB Universitas Brawijaya. 2 (2) : pp. 1-27.

Khomsiyah dan Indriantoro N. 1998. Pengaruh Orientasi Etika terhadap Komitmen dan Sensitivitas Etika Auditor Pemerintah di DKI Jakarta. Jurnal Riset Akuntansi Indonesia. 1 (1) : pp. 13-28.

Kristianti, I. 2012. "Pengaruh Tipe Kepribadian dan Penerimaan Perilaku Disfungsional terhadap Audit Judgement" (tesis). Salatiga: Universitas Kristen Satya Wacana.

Kuncoro, Mudrajad. 2013. Metode Riset untuk Bisnis dan Ekonomi. Edisi 4. Jakarta: Erlangga.

Lau, T.C, Choe, K.L, dan Tang, L.P. 2013. The Moderating Effect of Religiosity in the Relationship between Money Ethics and Tax Evasion. Asian Social Science. 9 (11) : pp. 213-220.

Lindrianasari, Jogiyanto, Supriyadi, dan Miharjo, S. 2012. Kepribadian sebagai Pemoderasi Hubungan Persepsi CEO atas Kompensasi yang Diterima pada Keinginan COE untuk Keluar Perusahaan Secara Sukarela. Simposium Nasional Akuntansi XV. Banjarmasin 20-23 September.

Lucyanda, J. 2012. Faktor-Faktor yang Mempengaruhi Perilaku Etis Mahasiswa Akuntansi Universitas Bakrie. Media Riset Indonesia. 2 (2) : pp. 113-131.

Mastracchio, N. J. 2005. Teaching CPAs About Serving the Public Interest, The CPA Journal.

Murray, D. 1990. The Performance Effect of Participative Budgeting: An Integration of Intervening and Moderating Variables. Behaviour Research In Accounting. 2: pp. 104-121. 
Nkundabanyanga, S. K.; Mpamizo, B.; Omagor, C.; and Ntayi, J. M. 2011. International Journal of Marketing Studies. 3 (4) : pp. 40-49.

Normadewi, B. 2012. Analisis Pengaruh Jenis Kelamin dan Tingkat Pendidikan terhadap Persepsi Etis Mahasiswa Akuntansi dengan Love of Money sebagai Variabel Intervening. Jurnal Akuntansi Universitas Diponegoro.

Novius, A. 2008. "Perbedaan Persepsi Intensitas Moral Mahasiswa Akuntansi dalam Proses Pembuatan Keputusan Moral" (tesis) Semarang: Universitas Diponegoro.

Nugrahaningsih, P. 2005. Analisis Perbedaan Perilaku Etis Auditor di KAP dalam Etika Profesi (Studi terhadap Peran Faktor-Faktor Individual: Locus of Control, Lama Pengalaman Kerja, Gender, dan Equity Sensitivity). Simposium Nasional Akuntansi VIII. Solo 15-16 September.

Pradanti, N.R dan Prastiwi, A. 2014. Analisis Pengaruh Love of Money terhadap Persepsi Etis Mahasiswa Akuntansi. Journal of Accounting Universitas Diponegoro. 3 (3) : pp. 1-12.

Purnamasari, St.V. 2006. Sifat Machiavellian dan Perkembangan Moral: Anteseden Independensi dan Perilaku Etis Auditor. Simposium Nasional Akuntnsi IX. Padang 23-26 Agustus.

Robetson, T., Baron, H., Gibson, P., Maclver, R. and Nyfield. 2000. Conscientiousness and Managerial Performance. Journal of Occupational and Organizational psychology. 73 (2) : pp. 171-180.

Rosianti, C. dan Mangoting, Y. 2014. Pengaruh Money Ethics terhadap Tax Evasion dengan Intrinsic dan Extrinsic Religiosity sebagai Variabel Moderating. Tax \& Accounting Review. 4 (1) : pp. 1-11.

Rustiarini, Ni Wayan. 2013. Sifat Kepribadian dan Locus of Control Sebagai Pemoderasi Hubungan Stress Kerja dan Perilaku Disfungsional Audit. Simposium Nasional Akuntnsi XVI. Manado 25-28 September.

Sadjiarto, R.A. dan Foerthiono, A.N. 2014. Faktor-Faktor Yang Mempengaruhi Mahasiswa Akuntansi Berkarir Sebagai Akuntan Publik Dengan Persepsi Etis Skandal Akuntansi Sebagai Variabel Intervening. Tax \& Accounting Review. 4 (2): pp. 1-7.

Sanusi, Anwar. 2014. Metodologi Penelitian Bisnis. Cetakan keempat. Jakarta: Salemba Empat.

Saputri I.G.A.Y. 2015. Pengaruh Sifat Machiavellian dan Tipe Kepribadian pada Perilaku Disfungsional Auditor. E-Jurnal Akuntansi Universitas Udayana. 13 (2) : pp.429-445. 
Skyrme, P., Wilkinson, L., Abraham, J. D., and Morrison, J.D. 2005. Using Personality to Predict Outbound Call Center Job Performance. Applied Human Resource Management Research. 10 (2) : pp. 89-98.

Stead, W.E., Worrel D.L., and Stead J.G. 1990. An Integrative Model for Understanding and Managing Ethical Behavior in Business Organizations. Journal of Business Ethics. 9 (3) : pp. 233-242.

Sugiyono. 2009. Metode Penelitian Bisnis Kuantitatif, Kualitatif dan R\&D. Bandung: Alfabeta Cipta.

,2010. Metode Penelitian Bisnis. Cetakan ke 15. Bandung:

Alfabeta.

,2014. Metode Penelitian Bisnis (Pendekatan Kuantitatif, Kualitatif dan $R \& D)$. Cetakan ke 20. Bandung: Alfabeta.

2015. Metode Penelitian Tindakan Komprehensif (Untuk Perbaikan Kinerja dan Pengembangan Ilmu Tindakan). Cetakan ke 1. Bandung: Alfabeta

Suliani, M. 2010. Pengaruh Pertimbangan Etis, Perilaku Machiavelian, dan Gender dalam Pembuatan Keputusan Etis Mahasiswa. Jurnal Akuntansi dan Auditing. 7 (1) : pp. 62-79.

Tang, T. and Chiu, R. 2003. Income, Money, Ethics, Pay Satisfaction, Commitment, and Unethical Behavior: Is the Love of Money the Root of Evil for Hong Kong Employees?. Journal of Business Ethics. 46 (1) : pp. 13-30.

Tang, T. L. P. 2002. Is 'The Love of Money' The Root of All Evil? Or Different Strokers for Different Folks: Lesson in 12 Countries. BRC Papers on CrossCultural Management. pp.1-46.

Tang, T. T.L.T., and Homaifar, B. 2006. Income, the love of money, pay comparison, and pay satisfaction, Race and gender as moderatos. Journal of Managerial Psichology. 21 (5) : pp.476-491.

Tang, T., Kim, J., \& Tang, D. 2000. Does attitude towards money moderate the relationship between intrinsic job satisfaction and voluntary turnover?. Journal Human Relation. 53 (2) : pp. 213-45.

Tang, T., Tang, D., \& Luna-Arocas, R. 2005. Money profiles: the love of money, attitudes, and needs. Personnel Review. 34 (5) : pp. 603-24.

Tang,T.L.P. 1992. The moderating of Money Revisited: The Development of the Money Ethic Scale. Journal of Organizational Behaviour. 13 : pp. 197-202.

Utama, M.S. 2016. Aplikasi Analisis Kuantitatif. Denpasar: Cv. Sastra Utama. 
Marce Sherly Kase, H. Bambang Suprasto dan Maria M. Ratna Sari. Conscientiousness......

Widarno, B. 2007. Profil dan Kompetensi Sarjana Akuntansi. Jurnal Ekonomi dan Kewirausahaan. 7 (2) : pp. 150-159.

Widyasmono, F.H. 2012. Perspektif tentang Etika Profesi menurut Akuntan Publik dan Akuntan Pendidik. Jurnal Berkala Ilmiah Mahasiswa Akuntansi Unika Widya Mandala. 1 (2) : pp. 71-77. 